\title{
Experimental and Theoretical Investigation of Asymmetric Induction in the Synthesis of Disubstituted Cyclohexadienes via Chiral Benzene Chromium Complexes
}

\author{
Gerald Bernardinelli ${ }^{a}$ ), Allan Cunningham, Jr. ${ }^{b}$ ), Chantal Dupréb), E. Peter \\ Kündig $\left.^{\mathrm{b}}\right)^{*}$, Dominique Stussi ${ }^{\mathrm{c}}$ ), and Jacques Weber ${ }^{c}$ )
}

Abstract. A series of $\left[\mathrm{Cr}(\right.$ benzene $\left.)(\mathrm{CO})_{2} \mathrm{~L}\right]$ complexes with $\mathrm{L}=\mathrm{PPh}_{3}, \mathrm{P}(\mathrm{OMe})_{3}, \mathrm{PPh}_{2}$ $((-)$-menthyl $), \mathrm{P}(\mathrm{OPh})_{2}(\mathrm{O}-(-)$-menthyl $), \mathrm{P}(\mathrm{O}-(-) \text {-menthyl })_{3}$ were subjected to a nucleophile addition/acylation sequence to give trans-5,6-disubstituted cyclohexadienes. Low-to-moderate asymmetric induction was observed with the chiral ligands. Experimental and theoretical evidence for an alkylation at the metal center trans to the $\mathrm{P}$ ligand is presented, and a crystal structure determination of a $\left[\mathrm{Cr}\left(\eta^{5}-\right.\right.$ cyclohexadienyl $\left.)\left(\mathrm{P}(\mathrm{OMe})_{3}\right)(\mathrm{CO})_{2} \mathrm{SnPh}_{3}\right]$ complex is included.

\section{Introduction}

We have recently shown that trans5,6-disubstituted cyclohexadienes $\mathbf{B}$ can be obtained via a one pot reaction sequence which involves the sequential addition of a nucleophile and an electrophile to the readily accessible $[\mathrm{Cr}$ (benzene) $(\mathrm{CO})_{3}$ ] complex A (Scheme I) [1]. In this article, we show that at this stage chiral non-racemic cyclohexadienes can be obtained with moderate asymmetric induction via this methodology by substituting a CO ligand with a chiral P ligand.

As changes in the electron density at the metal center (i.e. by the replacement of a $\mathrm{CO}$ ligand by a phosphine or phosphite) can drastically alter the reactivity of a complex [2], our first objective was to prepare simple achiral derivatives of this class of compounds and to verify that they could also be converted to cyclohexadienes 3 (Scheme 2) by the same reaction sequence. In parallel, to rationalize reactivity, we have carried out a theoretical study of the reactivity of the modified arene complexes towards nucleophilic addition and of the cyclohexadienyl intermediates towards electrophilic addition.

\section{Theoretical Model}

Our model is based on a local reactivity index made of the interaction energy $E_{\mathrm{int}}(\vec{r})$ between an organometallic substrate $S$ and an incoming electrophilic or nucleophilic reactant $\mathbf{R}$ located in $\vec{r}$, which is expressed as:

$E_{\mathrm{int}}(\vec{r})=E_{\mathrm{es}}(\vec{r})+E_{\mathrm{cl}}(\vec{r})+E_{\mathrm{ex}}(\vec{r})$ where $E_{\mathrm{cs}}, E_{\mathrm{cl}}$, and $E_{\mathrm{cx}}$, are the electrostatic, charge-transfer, and exchange energy components, respectively. Whereas $E_{\mathrm{es}}$ and $E_{\mathrm{ct}}$ are evaluated in the framework of the extended Hückel quantum chemical method [3], using the electrostatic potential and the supermolecule approach, respectively, $E_{\mathrm{cx}}$ is calculated from a parametrized potential of Buckingham type [4][5]. The reactivity index is such that negative (or positive) values of $E_{\text {int }}$ correspond to S-R attractive (repulsive) interactions. The regions where $E_{\mathrm{int}}$ is minimum are, therefore, the most reactive sites of $S$ towards attack by $\mathrm{R}$. To have $E_{\text {int }}$ values that depend only on the position of R and not on its orientation, two spherically symmetric model reactants have been chosen: a proton with a virtual $1 \mathrm{~s}$ orbital for the electrophile and an $\mathrm{H}^{-}$ion with two $1 \mathrm{~s}$ electrons for the nucleophile.

We have employed two different molecular graphics representations of $E_{\text {int }}: i$ ) the molecular surface of $S$, color-coded according to the $E_{\text {int }}$ value (red: most favorable sites of attack); ii) the isoenergy surfaces of $E_{\text {int }}$ represented as three-dimensional solid models.

\section{Results and Discussion}

The structure and reactivity of $\left[\mathrm{Cr}\right.$ (benzene) $\left.(\mathrm{CO})_{3}\right]$ (1a) have been the subject of intensive investigations in organometallic chemistry. It is generally accepted that metal-benzene bonding leads to a net intramolecular charge transfer from the ring to the carbonyls, with the result that this compound is easily attacked by a nucleophile on the exo-face of the ring. Fig. 1 represents the $E_{\mathrm{in}}$ reactivity index calculated for the nucleophilic attack of this compound, which shows that, indeed, the most reactive site is located on the exo-face of the ligand ring. For comparison, the same index is also displayed for an uncoordinated benzene molecule. It is immediately seen that, as expected, an important change in reactivity accompanies benzene complexation: whereas for the isolated aromatic ring one observes essentially slightly negative iso-

\footnotetext{
${ }^{*}$ Correspondence: Prof. E.P. Kündigb)

a) Laboratoire de Cristallographie

Université de Genève

24, quai Ernest-Anserme

$\mathrm{CH}-1211$ Genève 4

h) Département de Chimie Organique,

Université de Genève

30, quai Ernest-Ansermet

CH-1211 Genève 4

c) Département de Chimie Physique, Université de Genève

30, quai Ernest-Ansermet

$\mathrm{CH}-1211$ Genève 4
}

Scheme 1

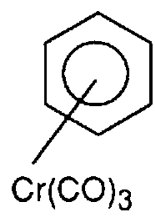

$\frac{\text { 1. LiR }}{\text { 2. R'X, CO }}$

A<smiles>[R]C(=O)[C@H]1C=CC=C[C@@H]1[R]</smiles>

B 


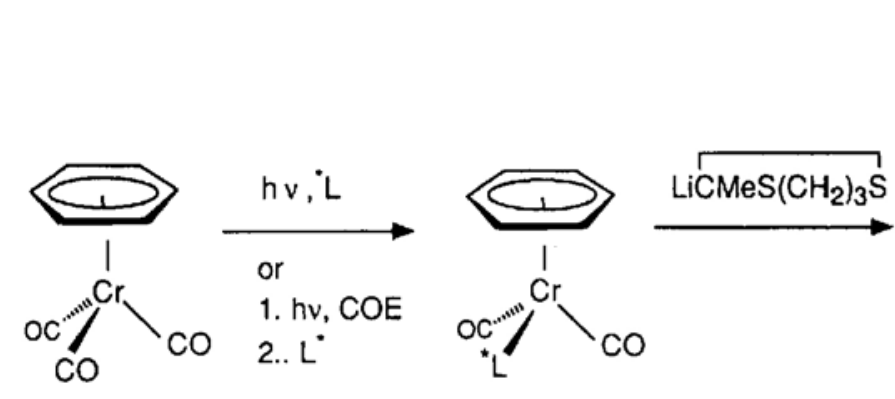

1a
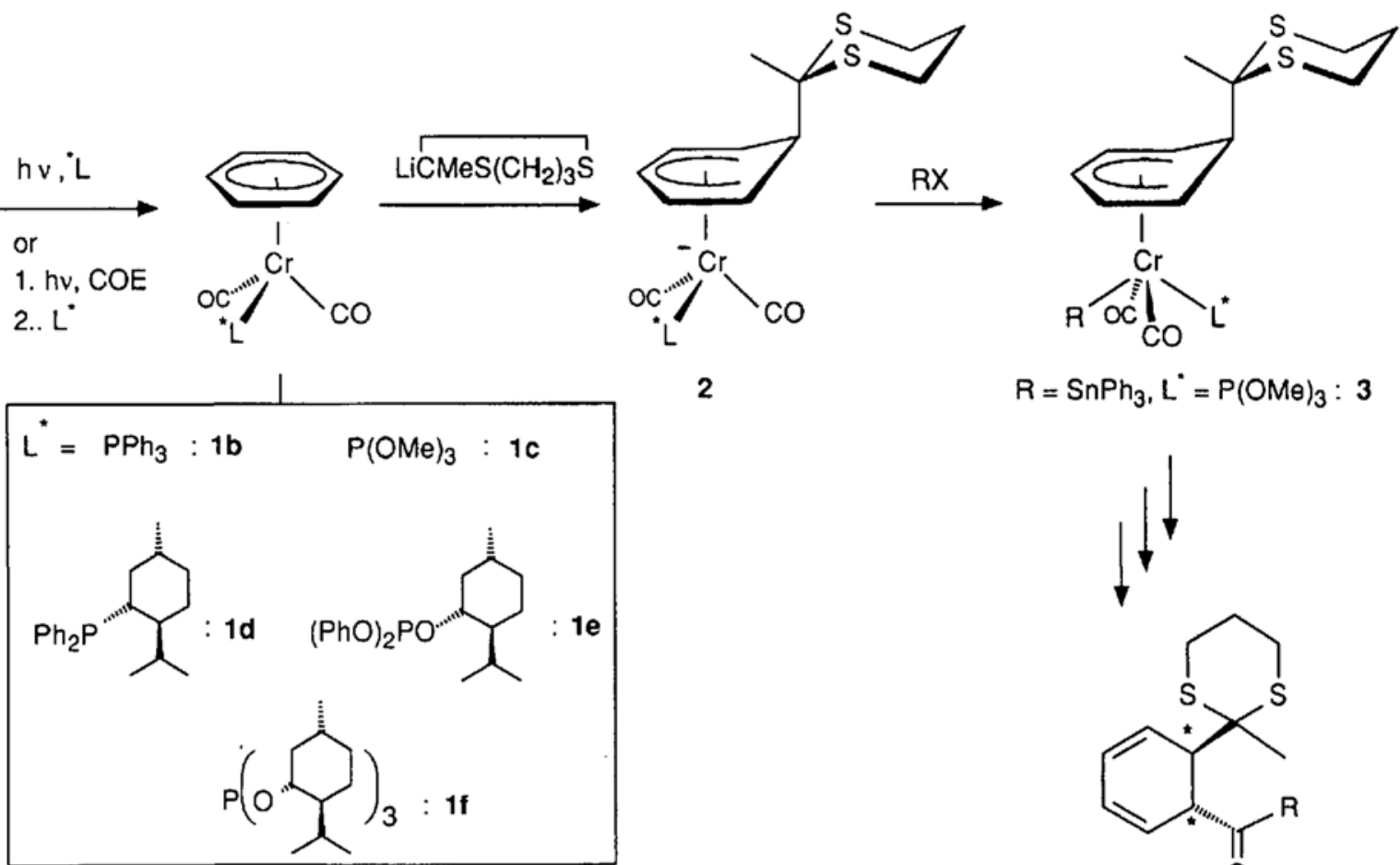

2

$\mathrm{R}=\mathrm{SnPh}_{3}, \mathrm{~L}^{\circ}=\mathrm{P}(\mathrm{OM} \theta)_{3}: 3$

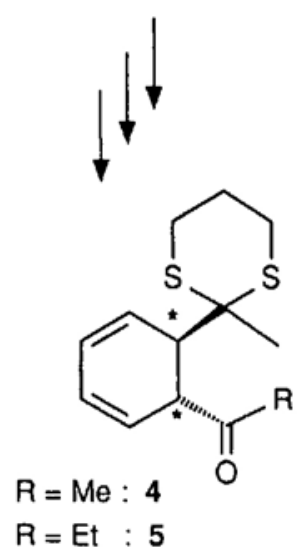

Table. Nucleophile Addition/Acylation Reaction with Complexes 1a-f

\begin{tabular}{|c|c|c|c|c|c|c|c|c|c|c|}
\hline Entry & Complex & $\mathrm{RX}$ & Decompl. a) & $\left.T^{b}\right)\left[{ }^{p}\right]$ & & & Product & $\begin{array}{l}\text { Yield") } \\
{[\%]}\end{array}$ & $\begin{array}{l}\left.\mathrm{ee}^{\mathrm{d}}\right) \\
{[\%]}\end{array}$ & $\begin{array}{l}\text { Absolute }{ }^{e} \\
\text { configuration }\end{array}$ \\
\hline 1 & 1a $(\mathrm{L}=\mathrm{CO})$ & MeI & $\mathrm{CO}$ & -196 & $\rightarrow$ & 20 & 4 & $\left.89^{f}\right)$ & - & - \\
\hline 2 & 1a & EtI & $\mathrm{CO}$ & -196 & $\rightarrow$ & 20 & 5 & $\left.81^{f}\right)$ & - & - \\
\hline 3 & $\mathbf{1 b}\left(\mathrm{L}=\mathrm{PPh}_{3}\right)$ & MeI & $\mathrm{CO}$ & -196 & $\rightarrow$ & 20 & 4 & 69 & - & - \\
\hline 4 & 1c $\left(\mathrm{L}=\mathrm{P}(\mathrm{OMe})_{3}\right)$ & MeI & $\mathrm{CO}$ & -196 & $\rightarrow$ & -50 & 4 & 60 & - & - \\
\hline 5 & 1d $\left(\mathrm{L}=((-)\right.$-menthyl $\left.) \mathrm{PPh}_{2}\right)$ & MeI & $\mathrm{CO}$ & -196 & $\rightarrow$ & -50 & 4 & 60 & 8 & SS \\
\hline 6 & 1d & EtI & $\mathrm{CO}$ & -196 & $\rightarrow$ & -50 & 5 & 44 & 19 & SS \\
\hline 7 & $1 \mathbf{e}\left(\mathrm{L}=\left((-)\right.\right.$-menthyl-O) $\left.\mathrm{P}(\mathrm{OPh})_{2}\right)$ & MeI & $\mathrm{CO}$ & -196 & $\rightarrow$ & -50 & 4 & 55 & 14 & $R R$ \\
\hline 8 & le & MeI & $\mathrm{P}(\mathrm{OPh})_{3}$ & -78 & $\rightarrow$ & -50 & 4 & 91 & 16 & $R R$ \\
\hline 9 & 1e & EtI & $\mathrm{CO}$ & -196 & $\rightarrow$ & -50 & 5 & 67 & 28 & $R R$ \\
\hline 10 & If $\left(\mathrm{L}=\mathrm{P}(\mathrm{O}-(-) \text {-menthyl })_{3}\right)$ & MeI & $\mathrm{CO}$ & -196 & $\rightarrow$ & -50 & 4 & 54 & 40 & SS \\
\hline 11 & if & MeI & $\mathrm{P}(\mathrm{OPh})_{3}$ & -78 & $\rightarrow$ & -50 & 4 & 70 & 31 & ss \\
\hline 12 & If & EtI & $\mathrm{P}(\mathrm{OPh})_{3}$ & -78 & $\rightarrow$ & -50 & 5 & 57 & 21 & SS \\
\hline
\end{tabular}

a) Either 5 bar $\mathrm{CO}$ or 3 equiv. of $\mathrm{P}(\mathrm{OPh})_{3}$.

$\left.{ }^{b}\right)$ Temperature of addition of alkyl halide and ligand used in the decomplexation, reaction temperature.

c) Isolated product after flash chromatography.

d) The enantiomeric excess was determined by 'H NMR with the chiral shift reagent tris[3-(heptafluoropropylhydroxymethylene)-4-camphorato]europium(III). [ $\left.\mathrm{Eu}(\mathrm{hfc})_{3}\right]$.

c) Absolute configuration of the major product. The absolute configuration indicated is based on an X-ray structure of the Diels-Alder adduct of RR-4 with (R)- $N$-1-phenylethylmaleimide. This was obtained by fractional crystallization of the minor diastereoisomer obtained from the reaction of product 4 from Entry 10.

f) Results taken from [ $1 \mathrm{a}]$ and included for comparison. 


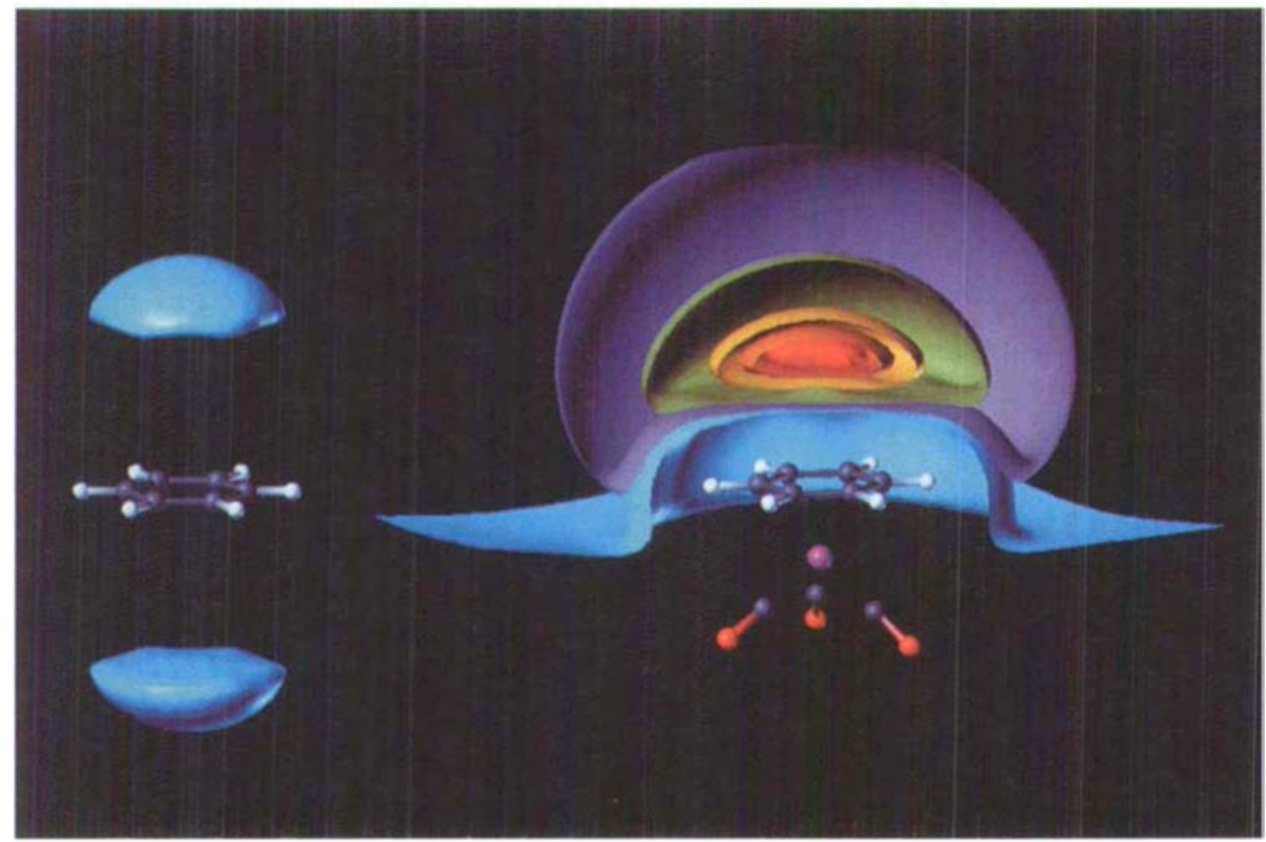

Fig. 1. Structural models of benzene (left) and $\left[\mathrm{Cr}\left(\eta^{6}\right.\right.$-benzene $\left.)(\mathrm{CO})_{3}\right]$ (right) represented together with solid models of $\mathrm{E}_{\text {int }}$ isovalue surfaces calculated for nucleophilic attack. Color-coding of the surfaces: blue $=-0.15$, purple $=-5.0$, green $=-10.0$, yellow $=-15.0$, brown $=-17.0$ and red $=-18.0$ $\mathrm{kcal} / \mathrm{mol}$.

energy envelopes centered on the $C_{6}$ axis above and below the molecular plane (representative of a weak van der Waals interaction) the situation changes dramatically for the coordinated arene. In the latter case, several imbricated surfaces are found at much lower energies, revealing as expected an important activation of the benzene ring through coordination to the electrophilic $\mathrm{Cr}(\mathrm{CO})_{3}$ group. As a consequence, our theoretical results show that the initial nucleophilic attack is likely to occur on the face opposite to the metal of complexed benzene, as has been found in experiment [6].

Preliminary reactions with $[\mathrm{Cr}(\mathrm{ben}$ zene) $(\mathrm{CO})_{2} \mathrm{~L}$ ] complexes were carried out with the triphenylphosphine $\left(\mathbf{1 b}, \mathrm{L}=\mathrm{PPh}_{3}\right)$ [7] and trimethylphosphite (1c, L = $\left.\mathrm{P}\left(\mathrm{OCH}_{3}\right)_{3}\right)[8]$ derivatives. The former was prepared in $74 \%$ yield by direct irradiation of a solution of $\left[\mathrm{Cr}\right.$ (benzene) $\left.(\mathrm{CO})_{3}\right]$ (1a) and $\mathrm{PPh}_{3}$ at $15^{\circ}$ with a $125 \mathrm{~W}$ high pressure $\mathrm{Hg}$ lamp using a Pyrex filter. As this procedure when applied to $1 \mathrm{c}$ gave a mixture of 1a, 1c, and the corresponding diphosphite complex, we used a two-step sequence via irradiation of $1 \mathrm{a}$ in the presence of a large excess of cyclooctene, followed by reaction of the intermediate olefin complex $(1, \mathrm{~L}=$ cyclooctene $)$ by $\mathrm{P}\left(\mathrm{OCH}_{3}\right)_{3}$ [9]. This method allowed the preparation of $1 \mathrm{c}$ in $81 \%$ yield. These two procedures were applied in the preparation of the analogous chiral phosphine and phosphite complexes (see Table).

The complexes $\mathbf{1 b}$ and $\mathbf{1 c}$ were then subjected to the 'double addition' reaction conditions (Scheme 2). Throughout this study, the nucleophile used was 2-lithio- 2-methyl-1,3-dithiane and the electrophile either MeI or EtI, or, for the isolation of intermediate $3, \mathrm{ClSnPh}_{3}$. Typically, the complexes were added as solids to 1.1 equiv. of 2-lithio-2-methyl-1,3-dithiane in THF $(10 \mathrm{ml} / \mathrm{mmol})$ at $-78^{\circ}$ followed by the addition of HMPA $(3 \mathrm{ml} / \mathrm{mmol})$. After stirring at $0^{\circ}$ for $15-20 \mathrm{~h}$, the reaction mixture was treated with an excess of alkyl halide ( 10 equiv.) and $\mathrm{CO}(\approx 5 \mathrm{bar})$ at $-196^{\circ}$ (or an excess of alkyl halide and 3 equiv. of $\mathrm{P}(\mathrm{OPh})_{3}$ at $\left.-78^{\circ}\right)[10]$, then allowed to warm slowly to the desired temperature. Workup yielded the trans-disubstituted cyclohexadiene 4. As the Table shows, the phosphine derivatives led to somewhat lower yields than the phosphite derivatives and the parent tricarbonyl complex. This can be attributed to the first step of the mechanism, i.e. the addition of the nucleophile to the complexed arene. As the phosphine (and to a lesser extent the phosphite) complexes are more electronrich, they are less susceptible to nucleophilic attack. For the same reason, the resulting anions, $\mathbf{2 b}-\mathbf{f}$, are expected to be better nucleophiles than their tricarbonyl counterpart 2a. Experimentally, this latter assumption has been verified. Whereas 2a requires temperatures near $0^{\circ}$ to react with primary alkyl iodides [1a], $\mathbf{2 b - f}$ can be alkylated at $-50^{\circ}$.

Having demonstrated the successful conversion of $1 \mathrm{~b}$ and $1 \mathrm{c}$ to 4 , we then investigated the possibility of asymmetric induction. Given the proximity of a chiral ligand L to the site of alkylation, one could anticipate diastereoselectivity upon alkylation of the intermediate 2. Provided that the carbonyl insertion and acyl migration steps are fast, this diastereoselectivity could be partially or entirely conserved in the

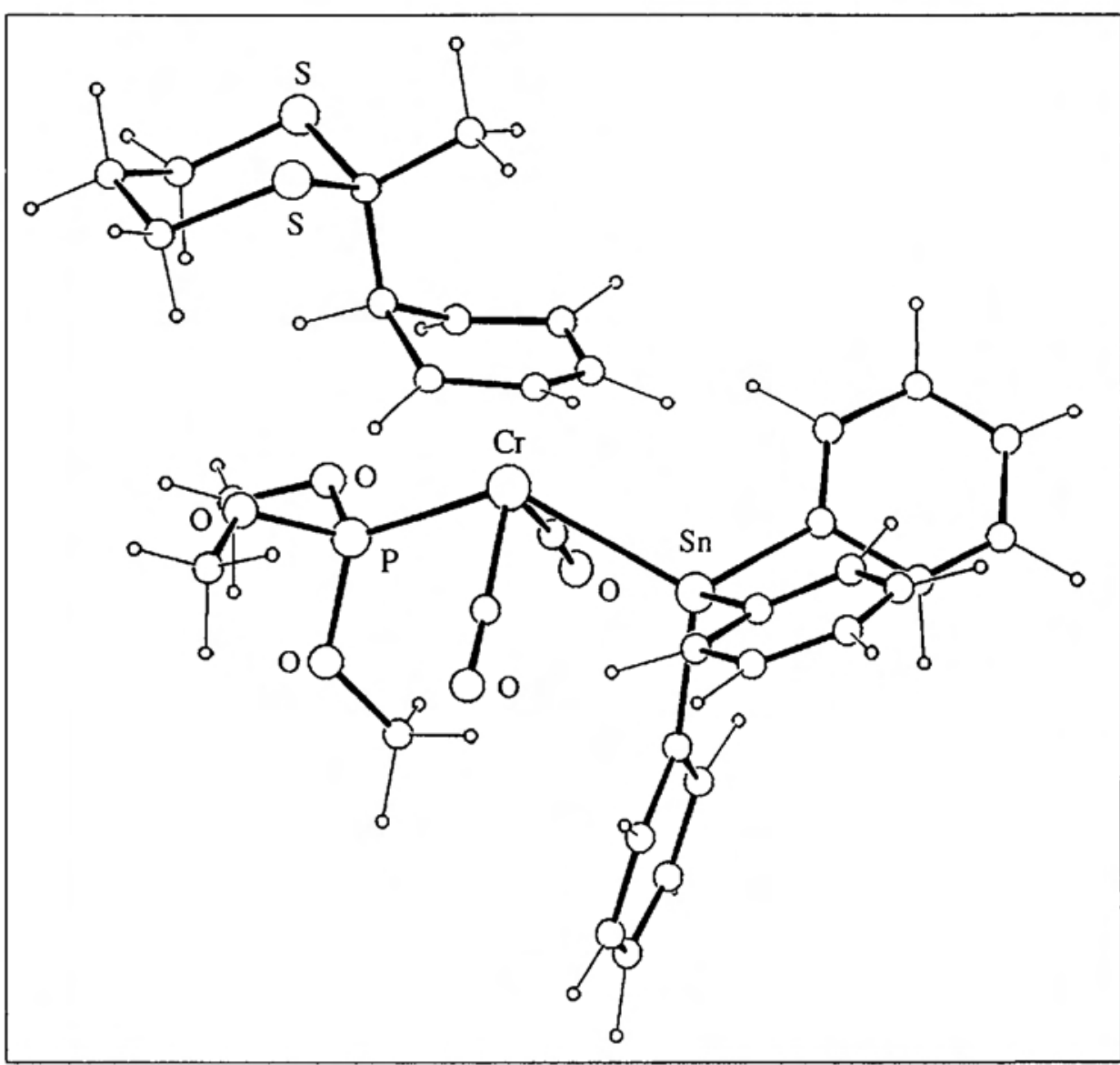

Fig. 2. X-Ray crystal structure of complex 3 


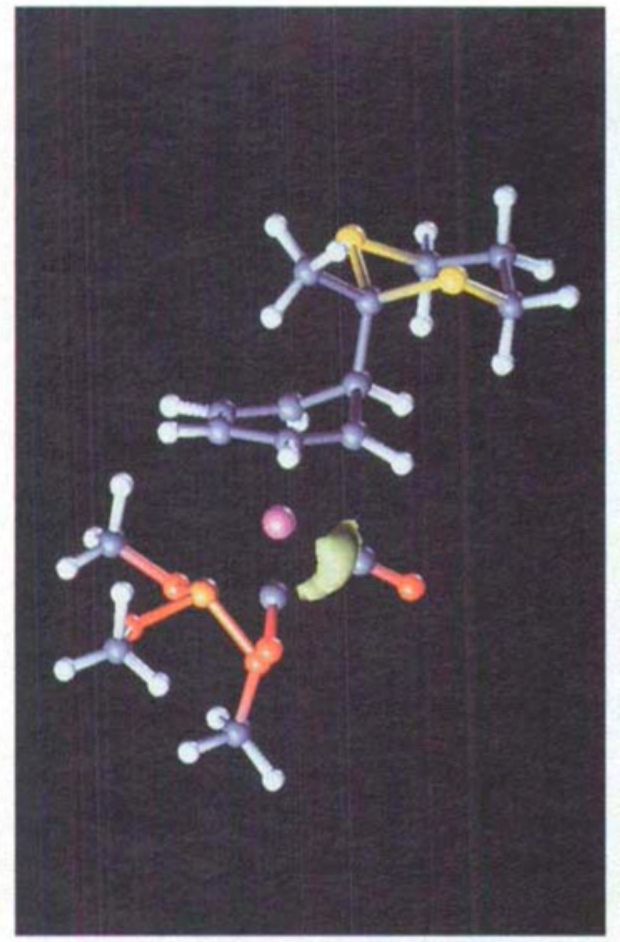

Fig. 3. Structural model of complex $2 \mathrm{c}$ represented together with a green-colored solid model of the $\mathrm{E}_{\text {in }}$ isovalue surface at $-250 \mathrm{kcal} / \mathrm{mol} \mathrm{calcu}$ lated for electrophilic attack

final product. However, alkylation can also take place trans to the phosphorous ligand leading to an intermediate which is achiral at the metal center. There is strong evidence that the reaction takes place via this second pathway. From the reaction of $2 \mathrm{c}$ with $\mathrm{ClSnPh}_{3}$, a single product 3 was isolated. From the IR intensities of the metal-CO stretching modes an approximate $(\mathrm{OC}) \mathrm{M}(\mathrm{CO})$ angle of $120^{\circ}$ was calculated [11]. The trans-arrangement of the two $\mathrm{CO}$ ligands thus indicated was confirmed in the X-ray structure determination of $\mathbf{3}$ (Fig. 2).

While we cannot rule out that the transproduct derives from ligand reorganization of an initially formed cis-product, this seems improbable in view of computational results. The calculated interaction potential between $2 \mathrm{c}$ and an electrophile (Fig. 3) clearly favours addition trans to the phosphite ligand independent of the conformation (phosphite ligand or $\mathrm{CO}$ eclipsed to the $\mathrm{sp}^{3}$ cyclohexadienyl center). We note that for $\mathbf{2 a}$, calculations indicate the highest reactivity at the metal center trans to that $\mathrm{CO}$ which eclipses the $\mathrm{sp}^{3}$ center of the cyclohexadienyl ligand (Fig. 4). In trans-alkylation, between the COligands, asymmetric induction can arise from the preferential migratory insertion of one of the two diastereotopic CO's (in 3) and/or the acyl migration to one of the diastereotopic terminal cyclohexadienyl C-atoms.

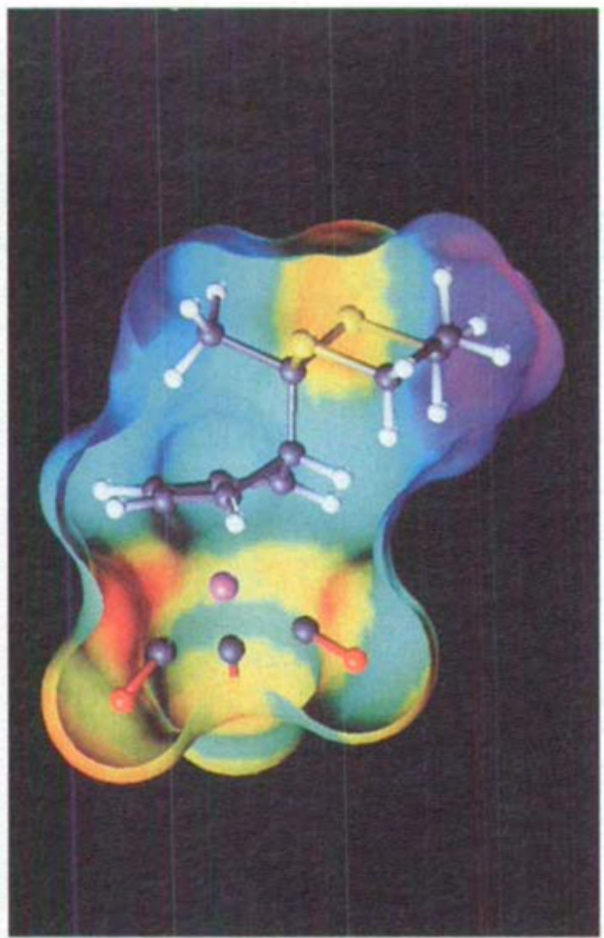

Fig. 4. Solid model of the molecular surface of complex $2 \mathrm{a}$ colored according to the $\mathrm{E}_{\text {int }}$ reactivity index calculated for electrophilic attack. The most reactive site correspond to the red zone located towards metal atom in trans-position with respect to the $\mathrm{CO}$ group eclipsing the $\mathrm{sp}^{3} \mathrm{C}$ atom of the ligand ring.

The Table shows first results of the nucleophile addition/acylation sequence with complexes containing $\mathrm{P}\left(\mathrm{OCH}_{3}\right)_{3}$ and $\mathrm{PPh}_{3}$ as well as three (-)-menthol-derived ligands, (menthyl)(diphenyl)phosphine [12], (menthyl)(diphenyl)phosphite [13], and trimenthylphosphite [15].

It is interesting to note that the (menthyl)(diphenyl)phosphite induces the opposite sense of chirality in the product than (menthyl)(diphenyl)phosphine and the more efficient trimenthylphosphite. Further studies with these and other chiral ligands are under way. In parallel, we are investigating the preparation and chemistry of chelating diphosphorous derivatives of (benzene)(tricarbonyl)chromium. A chelating chiral diphosphorous ligand can be expected to direct alkylation cis to the single CO ligand. This will eliminate the possible loss of asymmetric induction in the migratory insertion step and hopefully lead to higher diastereoselectivity in the product.

In conclusion, we have shown that the addition of two $\mathrm{C}$-substitutents across a benzene double bond is feasible with $\mathrm{Cr}$ complexes containing a Pligand. The computational results correctly predict the site of electrophilic attack of the cyclohexadienyl intermediate. While asymmetric induction via chiral $\mathrm{P}$ ligands has not yet reached useful levels, the first results using this approach are encouraging.
Financial support of this work by the Swiss National Science Foundation (grants No. 2027940.89 and 20-29856.90) is gratefully acknowledged.

[1] a) E. P. Kündig, A. F. Cunningham, Jr., P. Paglia, D. P. Simmons, Helv. Chim. Acta $1990,73,386$. For a synthetic application of this methodology see: b) E. P. Kündig, M. Inage, G. Bernardinelli, Organometallics 1991, 10, 2921.

[2] a) For a comparison of the $\mathrm{M}-\mathrm{CO}$ and the $\mathrm{M}-\mathrm{PR}_{3}$ bond see: A. J. Pearson, 'Metalloorganic Chemistry', Wiley, New York. 1985, pp. 3-5, e.g. in arene chromium chemistry see: b) G. Jaouen, R. Dabard, J. Organomet. Chem. 1974, 72, 337; c) G. Jaouen, A. Meyer, G. Simonneaux, J. Chem. Soc., Chem. Commun. 1975, 814; d) R. Dabard. G. Jaouen, G. Simmoneaux, M. Cais, D. H. Kohn, L. Lapid, D. Tatarsly, J. Organomet. Chem. 1980, 184,91; e) M. Cais, M. Kaftory, D. H. Kohn, D. Tatarsky, ibid. 1980. 184, 103; f) I. S. Butler, A. A. Ismail, Inorg. Chem. 1986, 25, 3910; g) V. Desobry, E. P. Kündig, Helv. Chim. Acta 1981, 64, 1288.

[3] R. Hoffmann, J. Chem. Phy's. 1963, 39. 1937.

[4] C. Daul, A. Goursot, P. Y. Morgantini, J. Weber, Int. J. Quant. Chem. 1990, 38, 623.

[5] J. Weber, P. Fluekiger, D. Stussi, P. Y. Morgantini, J. Mol. Struct. Theochem. 1991, 227,175 .

[6] M. F. Semmelhack, H. T. Hall, R. Farina, M. Yoshifuji, G. Clark, T. Bargar, K. Hirotsu, J. Clardy, J. Am. Chem. Soc. 1979, I01, 3535.

[7] a) W. Strohmeyer, F. J. Müller, Chem. Ber. $1969,102,3608$

[8] P. A. Brown, H. J. Lyons, A. R. Manning, Inorg. Chim. Acta 1970, 4, 428.

[9] a) G. Jaouen, Tetrahedron Lett. 1973, 5159; b) G. Jaouen, G. Simmoneaux, Inorg. Synth. 1979, 19, 17.

[10] The anionic cyclohexadienyl complexes are far better nucleophiles than $\mathrm{P}(\mathrm{OPh})_{3}$; hence, alkylation/carbonylation proceeds selectively.

[11] F. A. Cotton, G. Wilkinson, 'Advanced Inorganic Chemistry', Sthedn., Wiley, New York, 1988, pp. 1035-1037.

[12] a) J. D. Morrison, W. F. Masler, J. Org Chem. 1974, 39, 270; b) M. Tanaka, I. Ogata, Bull. Chem. Soc. Jpn. 1975, 48 1094.

[13] Synthesized from (-)-menthol and diphenylphosphorochloridite [14] in the presence of $\mathrm{Et}_{3} \mathrm{~N}$.

[14] a) F. Ramirez, Y. F. Chaw, J. F. Marecek. I. Ugi, J. Am. Chem. Soc. 1974, 96, 2429; b) W. Hewertson, B. C. Smith, R. A. Shaw, Inorg Synth. 1966, 8, 68 .

[15] Synthesized from (-)-menthol and phosphorous trichloride in the presence of $\mathrm{Et}_{3} \mathrm{~N}$. 